NOTAS

\title{
MINERÍA EN MÉXICO DURANTE EL SIGLO XVIII ¿AUGE O DECADENCIA?
}

Darío G. Ibarra*

\section{Resumen}

$\mathbf{E}$ nería en el siglo XVIII. Estudia la validez de la hipótesis que argumenta que durante el siglo mencionado esta industriatuvo una profunda crisis. Se concluye que no existe evidencia económica que sostenga esa hipótesis y que los parámetros utilizados que la sustentan no son los adecuados; por lo tanto, las conclusiones deben ajustarse hasta analizar los datos correctos.

Sin lugar a dudas quedan bastantes asuntos por descubrir respecto a la historiaeconómica de México; como muestra de ello, baste mencionar el debate suscitado en torno a la decadencia de la economía mexicana en el siglo XVII, la cual ha sido explicada tanto por la producción minera, ${ }^{1}$ como por la recolección de impuestos; ${ }^{2}$ además, exis-

* Alumno del ITAM.

${ }^{1}$ John H. Coatsworth, Los origenes del atraso, 1990, México, Alianza, Cap. I, "La historiografía económica de México", p. 28.

${ }^{2}$ John $\mathrm{H}$. Coatsworth, Los origenes del atraso..., op. cit, p. 23-6. Klein, Herbert y John Tepaske, The Seventeenth Century ten discrepancias sobre si hubo crisis o no. ${ }^{3}$ Dada la importancia que para la Nueva España tenía la industria minera, el análisis de ésta ha servido como indicador de la economía en el México colonial; sin embargo, muchas investigaciones en torno a la minería han carecido del rigor que otorga el enfoque económico, o bien el tratamiento que se les ha dado no ha sido el adecuado. Por ello, las conclusiones hasta ahora obtenidas deberán someterse a la luz de las herramientas que la economía otorga, y si lo que se ha obtenido es congruente con la teoría y la intuición económicas, deberá aceptarse como válido; en caso contrario, habrá que realizar nuevos estudios que contribuyan a la formación de una historia económica más precisa.

En el presente ensayo se hace un análisis económico de la industria minera en el siglo XVIII para verificar si

Crisis in New Spain Myth or Reality?, Past and Present, 90, 1981, p. 116-35.

${ }^{3}$ John $\mathrm{H}$. Coatsworth, Los origenes del atraso, op. cit., p. 21-36. 
NOTAS

existen razones, o no, para afirmar que esta industria estaba en crisis. ${ }^{4}$ Dicho análisis se basa fundamentalmente en los trabajos de John H. Coatsworth, en los datos existentes sobre la producción de metales preciosos así como de su precio en el mercado. Una vez determinado si existe evidencia para decir que la minería estaba en decadencia en el periodo mencionado, se consideran brevemente las condiciones económicas durante ese siglo y el siguiente para indagar porqué la industria minera no continuó siendo un motor de desarrollo económico.

\section{I}

Numerosos libros de historia de México han descrito el modo en que los primeros españoles que pisaron suelo americano apreciaban los metales preciosos como el oro y la plata; es ya leyenda que los soldados de Cortés que caían a los canales o en el lago,

${ }^{4}$ En la citada obra de Coatsworth, en el capítulo III, se argumenta que la industria minera entró en decadencia aproximadamente veinticinco afios antes de que terminara el siglo XVIII, es decir, casi 35 años antes de iniciado el movimiento de independencia. Coatsworth pretendió demostrar que la crisis de la industria minera se dió antes de la independencia (Los origenes op. cit., p. 58); sin embargo, los supuestos que plantea para demostrar su hipótesis parecen no ser los adecuados. En el curso del presente trabajo analizaremos sus argumentos y expondremos las razones por las cuales suponemos que sus conclusiones son equivocadas. durante los combates de la noche triste, perecieron hundidos en el fango por el peso del oro conquistado. Ello era provocado en gran medida por la creencia de que los metales preciosos, principalmente el oro, constituían la expresión suprema de la riqueza. Por otra parte, la necesidad de los reyes españoles de obtener ingresos para financiar sus gastos provocó que, a partir del descubrimiento de la primera mina en la nueva España en $1532,{ }^{5}$ se desatara una vertiginosa explotación de diferentes metales preciosos a lo largo y ancho del país.

Debe considerarse, además, que los españoles no mostraban tendencia a colonizar el campo; por otra parte, el déficit en la balanza de pagos, generado por la importación de bienes de carácter suntuoso de la metrópoli, debía ser saldada de alguna manera, y encontraron en la minería el lugar apropiado para compensar la balanza de pagos. La explotación de metales tuvo tal crecimiento que para fines del siglo XVI los metales preciosos representaban más del $80 \%$ de las exportaciones totales de la Nueva España. ${ }^{6}$

Tan pronto como fue iniciada la explotación minera, alrededor de las minas se construyeron haciendas que

${ }^{5}$ Mendizábal, Miguel Othón de, La minería y la metalurgia mexicana (1520-1943), 1980, México, Centro de Estudios Históricos del Movimiento Obrero Mexicano, p. 14-9.

${ }^{6} \mathrm{Brading}$, Mineros y comerciantes en México 1763-1810, 1975, México, Fondo de Cultura Económica, p. 22. Brading cita en una nota al pie de página los datos de Parry, The Spanish Seaborne Empire, p. 242-2. 
facilitaron la producción de granos para la alimentación de jornaleros y mulas, así como madera, cuero y otras materias primas para las minas; por ello, puede decirse que la prosperidad de las haciendas (por lo menos las del norte), siguieron de cerca los pasos del progreso de la minería. Las ganancias obtenidas de las minas sirvieron para colonizar provincias enteras, pues de este modo se consiguieron recursos que sufragaron los gastos de la colonización.?

De lo anterior se desprende que en sus inicios la minería fue un verdadero motor de la economía, pues la explotación minera trajo consigo el desarrollo de otras actividades económicas en la que encontraron trabajo indígenas, mestizos y los mismos españoles; además, permitió el intercambio comercial con la metrópoli. La teoría moderna del comercio internacional establece que el comercio entre naciones redunda en mayor bienestar para los países que comercializan bienes y/o servicios entre sí; sin embargo, muy probablemente habría que cuestionar si las condiciones bajo las cuales se realizaba el intercambio comercial provocó una mejor situación económica en la Nueva España, pues, como hemos visto, los bienes importados eran en su mayoría de naturaleza suntuaria; no obstante, el estudio del comercio exterior nos desvía del objeto del presente ensayo y su estudio deberá realizarse más ampliamente en otra ocasión.

${ }^{7}$ Brading, Mineros y comerciantes..., op. cit., p. 23.
El nacimiento de una hacienda necesariamente trajo consigo la construcción de caminos y la explotación de tierras, lo cual en conjunto se puede ver como un incremento en la producción nacional, fruto indirecto de la explotación minera. Nos atrevemos a conjeturar que la industria que estudiamos pudo devenir en un motor que siguiera fomentando la producción agregada nacional, pero en el siglo XIX no ocurrió así, ¿Qué fue lo que pasó? ¿Qué impidió a esta industria ser la punta de lanza que abriera el camino hacia el crecimiento económico? Coatsworth sostiene que la minería entró en decadencia en el siglo XVIII y que al iniciar el movimiento de independencia la industria ya estaba enferma ${ }^{8}$ y ésta sería la respuesta a las interrogantes planteados. En el siguiente capítulo discutiremos la validez de los razonamientos de Coatsworth y en el capítulo posterior habremos de dar respuesta a estas preguntas.

\section{II}

Coatsworth sostiene que la industria minera se encontraba ya en decadencia a fines del siglo XVIII, por lo que la revolución de independencia fue sólo la puntilla que terminó por hundirla totalmente.

Para demostrar lo anterior, apela a los datos que presentan los cuadros 1 y 2 .

${ }^{8}$ Coatsworth, Los orígenes..., op. cit., p. 58.

${ }^{9}$ Ibidem. 
NOTAS

Cuadro 1. Producción de metales preciosos. 1695-1814

$\begin{array}{lrlr}1695 / 99 & 19.6 & 1755 / 59 & 65.7 \\ 1700 / 04 & 25.3 & 1760 / 64 & 58.5 \\ 1705 / 109 & 28.5 & 1765 / 69 & 60.9 \\ 1710 / 14 & 32.8 & 1770 / 74 & 80.8 \\ 1715 / 19 & 35 & 1775 / 79 & 91 \\ 1720 / 24 & 50.3 & 1780 / 84 & 100.3 \\ 1725 / 29 & 52 & 1785 / 89 & 93.2 \\ 1730 / 34 & 52.5 & 1790194 & 109.7 \\ 1735 / 39 & 47.7 & 1795 / 99 & 121.2 \\ 1740 / 44 & 48.6 & 1800 / 04 & 104.6 \\ 1745 / 49 & 59.6 & 1805 / 09 & 122 \\ 1750 / 54 & 64.6 & 1810 / 14 & 47.1\end{array}$

Fuente: Manuel Orozco y Berra, "Informe sobre la acuñación en las Casas de Moneda de la República", Anexo a la Memoria de la Secretaría de Fomento, México, 1857.

Cuadro 2. Índice de producción física de la minería, 1695-1814

80 $(1755-1759=100)^{10}$

$\begin{array}{lllr}169599 & 29 & 175559 & 100 \\ 170004 & 39 & 1760164 & 89 \\ 1705109 & 43 & 1765 / 69 & 93 \\ 171014 & 50 & 177074 & 123 \\ 1715 / 19 & 53 & 1775 / 9 & 139 \\ 172024 & 77 & 178084 & 153 \\ 1725 / 29 & 79 & 178589 & 142 \\ 173034 & 80 & 179094 & 167 \\ 1735 / 39 & 73 & 179599 & 185 \\ 1740444 & 74 & 180004 & 159 \\ 1745 / 49 & 91 & 1805109 & 186 \\ 175054 & 98 & 181014 & 72\end{array}$

Fuente: Cuadro 1.

${ }^{10}$ Ibidem, p. 59-60.

Las gráficas de los cuadros puede ayudarnos a ver mejor la tendencia de la producción: 
NOTAS

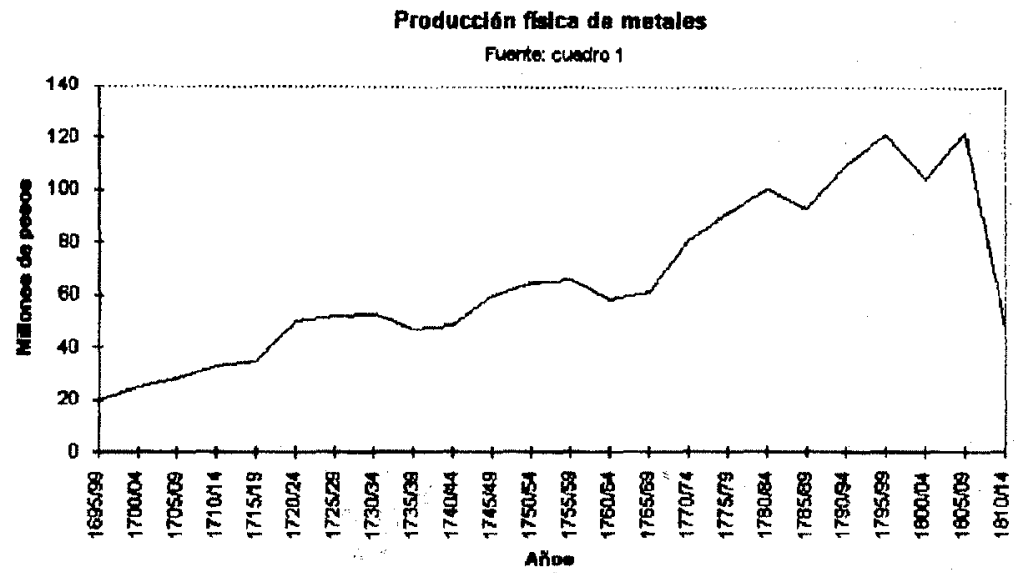

Indice de produccion fisice.

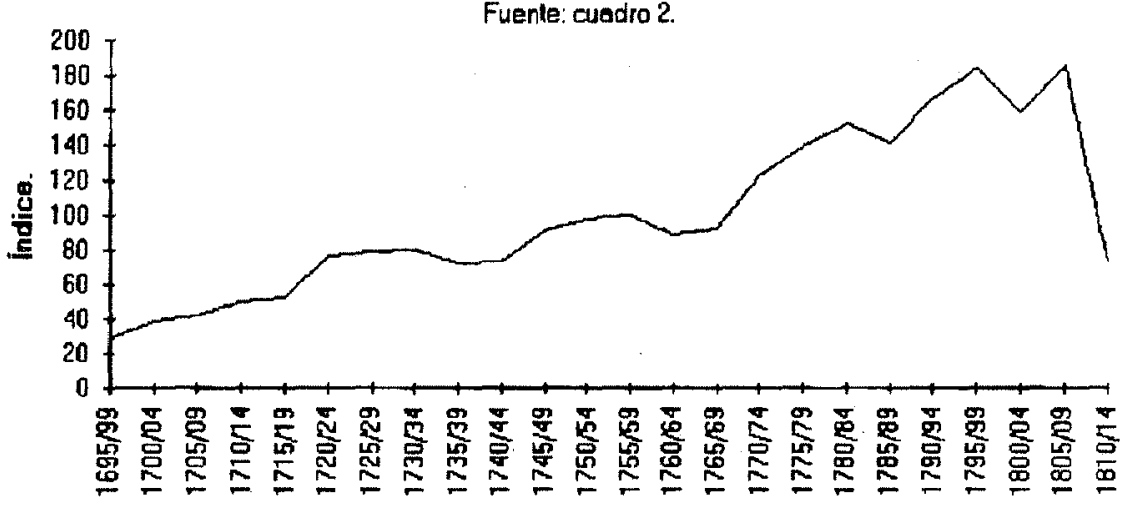

Ano

En las gráficas se puede observar que la tendencia de la producción es, en general, creciente; debe observarse que existen ciclos y que en algunas ocasiones la producción aumenta y en otras decrece, sin embargo, ese es un fenómeno observado en prácticamente todas las economías del mundo.

El siguiente paso de Coatsworth es deflactar la producción minera con los índices de Florescano y Rabell, pues dice:

"La producción física no siempre es el mejor instrumento para medir la productividad, puesto que no mide el aumento de la producción en términos del mercado. Los economistas definen la productividad como el rendimiento que tienen los 
NOTAS

factores escasos de la producción. Cuando el bien producido es dinero, habrá que expresar su valor en términos de su capacidad para obtener otros recursos. Sólo así podrán medirse los costos del mercado para generar el producto, contra el valor del producto en el mercado". ${ }^{11}$

Una vez deflactada la serie, muestra los siguientes datos en el cuadro 3 , que son expresados como índices en el cuadro 4.

Los índices de producción minera con deflactación y sin ella se pueden en la gráfica correspondiente.
No es difícil observar que el punto de producción máximo se alcanza en el quinquenio de 1775-1779 (atendiendo a la gráfica deflactada), y que en ningún momento, antes o después de este período, la producción alcanza un nivel superior. Coatsworth se muestra cauteloso al hacer hincapié en que los índices utilizados deben tomarse con reserva por provenir de productos agrícolas, pero argumenta que en todo caso son una buena aproximación para los fines deseados. Finalmente, dice que la industria minera era objeto de subsidio en materias primas tales como el azogue (mercurio), indispensable para la amalgamación de la plata.

Cuadro 3. Valor de mercado de los metales preciosos, 1695-1814 (en millones de pesos de 1775-1779)

Indioe do Floreenens

$1695 / 99$

$1700 \% 4$

$1705 \mathrm{ng}$

$1710 / 14$

$1719 / 19$

$1720 / 24$

$1725 / 29$

$1730 / 34$

$1735 / 39$

1740/44

$1745 / 49$

$1750 / 54$

$1755 / 59$

$1760 / 64$

$1765 / 69$

$1770 / 74$

$1775 / 79$

$1780 / 84$

$1785 / 89$

$1790 / 94$

$1795 / 99$

$1800 / 04$

1805109

$1810 / 14$
Indice de Rabol

13.

18.6

22

32.1

39.8

58.1

43.2

42.1

47.7

43.7

41.2

64.9

65.7

70

110.7

133.3

71,6

$\$ 1.7$

Fuente: Véase texto.

${ }^{11}$ Coatsworth, Los origenes..., op. cit., p. 63. 
NOTAS

Cuadro 4. Índice del valor de mercado de la producción de metales preciosos, 1695-1814.

$(1755-1759=100)$

\begin{tabular}{|c|c|c|c|}
\hline & Floresc uno & Rebell & Ptoduceri \\
\hline $1695 / 9$ & & $\boldsymbol{x}$ & $\boldsymbol{2}$ \\
\hline $1700 / 04$ & & 28.3 & 39 \\
\hline $170 \$ / 100$ & & 395 & 49 \\
\hline $1710 / 14$ & & 489 & 50 \\
\hline 171579 & & 60.6 & 53 \\
\hline $1720 / 24$ & 79.5 & 88.4 & $\pi$ \\
\hline $1725 \pi$ & 82.3 & 65.8 & 79 \\
\hline $1730 / 34$ & 79.4 & 64.1 & 80 \\
\hline $1735 / 39$ & 69.4 & 72.6 & 73 \\
\hline $1740 / 44$ & 62.1 & 65.5 & 74 \\
\hline $1745 / 49$ & 75.3 & 62.7 & 91 \\
\hline $1750 / 54$ & 763 & 988 & 98 \\
\hline $1755 / 59$ & 100.0 & 100.0 & 100 \\
\hline $1760 / 64$ & 87.1 & 106.5 & 89 \\
\hline $1765 / 69$ & 114.5 & & 93 \\
\hline $17 m / 74$ & 95.1 & 1685 & 123 \\
\hline $1775 / 9$ & 150.8 & $2 M 9$ & 139 \\
\hline 1780124 & 199.2 & & 153 \\
\hline 178589 & 64.8 & & 142 \\
\hline $1790 / 94$ & 1425 & & 167 \\
\hline $2795 / 99$ & 123.7 & 1090 & 185 \\
\hline 180004 & 102.7 & 78.7 & 159 \\
\hline 1805100 & 1055 & & 186 \\
\hline 1014 & 27.5 & & 72 \\
\hline
\end{tabular}

Fuente: Cuadros 2 y 3.

Indices de producción minera.

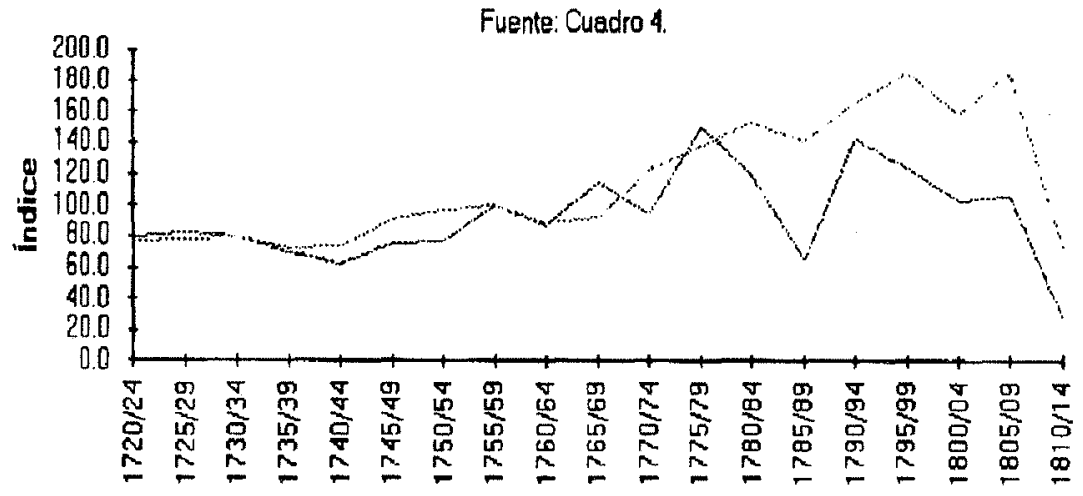

Ahn

Producción deflactada Producción física 
NOTAS

Si a lo anterior agregamos que la calidad de los metales extraídos era cada vez mas baja, el resultado natural es el de suponer que la industria estaba en crisis.

Los argumentos de Coatsworth son realmente seductores, una primera aproximación nos indicaría que efectivamente la minería estaba enferma. Sin embargo, un punto que es importante notar es que emplea el término "acuñación" como sinónimo de "producción", con lo cual deja fuera de su contabilización la producción de metales que circulaban en otras formas. ${ }^{12}$ En vista de que antes hemos mencionado que la mayor parte de la producción era acuñada, podemos suponer que los metales que circulaban en forma diferente a la de monedas era mínima y por lo tanto su circulación no sesgaría la información de modo significativo. Más importante que lo anterior es precisamente haber considerado como indicador de la productividad el término acuñación. Para entender la razón, debemos considerar un hecho singular: los metales preciosos extraídos al ser acuñados eran usados como dinero circulante, esto a primera vista no hace sino redescubrir lo evidente, pero debemos tomar en consideración que para que un bien pueda ser utilizado como dinero debe reunir varias características, entre ellas, que sea difícil de conseguir, que todo mundo lo

${ }^{12}$ Pérez Herrero, Pedro, El crecimiento económico Novohispano durante el siglo XVII: una revisión, Revista de Historia Económica $7: 1,1989$, p. 73. acepte como medio de cambio $\mathrm{y}$, de mayor importancia, que su valor intrínseco sea menor a lo que representa. ${ }^{13}$ En vista de la dualidad que presentaban los metales preciosos, al ser usados como bienes y como dinero, la producción de monedas no es el indicador adecuado para medir la eficiencia de una industria. En caso de hacerlo de esta manera, los resultados obtenidos dificilmente podrán ser considerados como correctos.

Ello ocurre así porque la producción de moneda sobreestima la producción física de metales, pues como hemos escrito en el párrafo anterior y como se ha explicado en la nota 13 , la moneda acuñada lleva consigo un va-

${ }^{13}$ El oro y la plata reúnen a la perfección estas características, de ahí que desde tiempos muy remotos hayan sido utilizados como dinero. De particula importancia en el presente caso, es que su valor intrínseco sea menor al que representan; así debe ocurrir porque de otra manera el público tenderá a atesorarlo en lugar de mandarlo a la circulación. Consideremos el sistema monetario actual: los billetes de $\mathrm{N} \$ 100$ ó $\mathrm{N} \$ 500$ tienen un valor muy por debajo de lo que realmente representan: en efecto, su costo de producción probablemente es de diez centavos (papel más impresión), no obstante la gente está dispuesta a intercambiarlos por bienes cuyo valor sea de N\$10? ó N\$500; esto es así porque saben que todo mundo los aceptará para realizar intercambios. Si los billetes tuvieran un valor superior a lo que representan (si por ejemplo un billete tuviera un valor de $\mathrm{N} \$ 600$ pero representara $\mathrm{N} \$ 500$, el público no lo dejaría circular y lo atesoraría para sí). 


\section{NOTAS}

lor intrínseco menor al que aparenta, es decir representa más de lo que en realidad vale, de otro modo no podría ser utilizada como dinero. Así es que si representa más de lo que vale o si representa más de lo que cuesta producirla, la medición de la productividad de la industria minera usando como parámetro la acuñación, conduce a resultados erróneos, pues no es este el modo adecuado para medir la productividad de la extracción de metales; en todo caso lo sería para la producción de dinero.

A pesar de la observación anterior, supongamos que efectivamente el indicador de la productividad de la industria minera utilizado por Coatsworth es el adecuado. Cuando deflacta lo hace porque, en general, los precios habían subido y por lo tanto el poder adquisitivo de la plata había caído. Sin embargo, los índices utilizados fueron formulados: a) el de Florescano, con los precios del maíz para diferentes años, y b) el de Rabell, construido con precios de comercio exterior. Como hemos mencionado, al deflactar hace la advertencia de que los índices utilizados tal vez no sean los mejores pero ofrecen resultados razonablemente exactos; mi particular opinión es que deflactar de ese modo puede sesgar los datos y arrojar resultados erróneos.

La razón se debe a que para que un índice de precios se construya adecuadamente y refleje lo que busca mostrar, debe ser construido a partir de una cesta de bienes; de hecho, los números índice son un promedio de los precios que se contemplan en la cesta; una vez construido el índice, servirá para medir el incremento en los precios de los bienes que incluye; además, si la cesta es suficientemente grande, podemos inferir para el resto de los bienes de la economía. Pero si tomamos en consideración solamente un bien o el conjunto de bienes de sólo un sector de la economía (en el presente caso el precio del maíz o de los productos de la balanza comercial), no es correcto decir que todos los bienes subieron en esa proporción y mucho menos deflactar con la serie obtenida, pues de hacerlo, existen altas posibilidades de obtener conclusiones incorrectas.

Además, debemos recordar una vez más que la mayor parte de los metales extraídos eran acuñados y por lo tanto convertidos en dinero circulante. En la cita que hemos hecho más arriba, Coatsworth señala que es conveniente deflactar porque con el dinero producido cada vez se podía comprar menos, esto es, su poder adquisitivo estaba en descenso. Otra forma de decir lo mismo es que había inflación. La economía neoclásica sostiene que la inflación es un fenómeno producido por un exceso de circulante en la economía, de modo tal que si el poder adquisitivo de la plata, respecto al resto de los bienes, estaba en descenso, se debía precisamente a que había mucho dinero en circulación, entonces fue el exceso de produción de metales lo que provocó que cayera el poder adquisitivo de la plata, lo cual es una señal de que la producción de metales estaba creciendo. ¿Puede decirse que una industria que, como consecuencia del exceso de 
NOTAS

producción, consigue que baje el precio del bien que produce, respecto de los precios de otros bienes, está en crisis? La respuesta no sólo depende del precio, es necesario analizar los costos: si la cantidad producida, multiplicada por el precio (estoes, el ingreso total), es mayor o igual que los costos en que incurrió, la industria permanece el el mercado, en caso opuesto se retira. El caso analizado indica que la minería consiguió que el precio cayera y a pesar de eso siguió produciendo, lo cual nos da una señal de que se estaban al menos cubriendo los costos con los ingresos obtenidos y por lo tanto la industria no estaba en crisis.

Coatsworth sostiene que la minería estaba subsidiada y que por ello era rentable seguir explotándolas, pero también menciona que los costos de producción se estaban elevando. Si consideramos ambos sucesos a la vez, podemos conjeturar que el subsidio pudo compensar el incremento en los costos de tal modo que ambos efectos quedarían cancelados. Desafortunadamente no tenemos datos que nos ayuden a estimar los costos de esta industria, pero en todo caso, el incremento en la producción es el principal indicador de que no había tal crisis.

Puede todavía argumentarse que el valor de la producción (esto es el producto multiplicado por su precio en el mercado), es el mejor indicador de la productividad de una industria, y como es esto lo que Coatsworth utiliza, entonces sus resultados son correctos. Hemos mencionado antes porqué en este caso particular no debe conside- rarse la acuñación como sinónimo de producción, pero, al igual que en la explicación anterior, supongamos que es correcto medirlo así. También hemos explicado porqué no se debió deflactar la información obtenida, pero esta explicación no estuvo sustentada sino en el razonamiento económico y no en datos explícitos; para tener la certeza de que no se debe deflactar, debemos tener presente que el objeto de la deflactación es la de tener la producción de una serie de tiempo, medida en términos de un año base, se debe descontar del valor de la producción el incremento en precios, para de este modo no sobrestimar el valor de lo producido. ${ }^{14}$ Pero solamente se debe deflactar si el precio del bien en cuestión también aumentó, pues el fin de deflactar es hacer que el precio sea manejado como si hubiera permanecido constante.

Bajo el supuesto de que es correcto medir la productividad como Coatsworth la hace, probaremos si existe o no razón para deflactar; observemos el

${ }^{14}$ Pongamos por caso el de las ventas de un almacen que en un año determinado vende $N \$ 100.00$ y que al año siguiente vende $N \$ 110.00$ mientras que la inflación anual fue de $5 \%$. A primera vista parecería que las ventas se incrementaron en $10 \%$, pero al descontar el efecto del incremento en precios, el resultado es que el incremento real de las ventas fue de aproximadamente $5 \%$. La deflactación de una serie de datos permite encontrar el incremento real de la producción una vez descontado el efecto inflacionario. 
NOTAS

Cuadro 5. Oro y plata producidos y acuñadas en México.

\begin{tabular}{|c|c|c|}
\hline Años & $\begin{array}{l}\text { Valor en } \\
\text { miles de pesos }\end{array}$ & $\begin{array}{l}\text { Cambio porcentual } \\
\text { en el valor } \\
\text { de la producción. }\end{array}$ \\
\hline $1701-1720$ & $125,352.38$ & \\
\hline $1721-1740$ & $175,162.69$ & 39.73622552 \\
\hline $1741-1760$ & $240,017.59$ & 37.025524 \\
\hline $1761-1780$ & $283,556.85$ & 18.14002768 \\
\hline $1781-1800$ & $425,756.28$ & 50.1484714 \\
\hline
\end{tabular}

Fuente: Humbold, Alejandro de. ${ }^{15}$

Cuadro 6. Plata y oro producidos kilogramos. ${ }^{16}$

valor de la producción midiéndola en períodos de 20 años (véase cuadro 5).

El paso siguiente es observar la producción de Oro y Plata midiéndola en kilogramos y por el mismo período (véase cuadro 6).

Veamos ahora los cambios porcentuales entre período y período y comparémoslos (véase cuadro 7).

${ }^{15}$ Humboldt, Alejandro de, Ensayo Politico sobre el reino de la Nueva España. tomo II, libro cuarto, capítulo XI, 1941, México, ed. Pedro Robledo, p. 302-3.
Cambios porcentuales en producción

Plata Oro

$\begin{array}{rr}40.873016 & 29.894938 \\ 30.444204 & 20.441176 \\ 21.727575 & 59.76801 \\ 53.507096 & -6.075659\end{array}$

En el cuadro 7 puede apreciarse claramente que el cambio en el valor de la producción es aproximadamente igual al cambio en la producción total (midiéndola por kilogramos), de donde se concluye que como aumentaron el valor de la producción junto con la producción en aproximadamente la misma proporción, el precio de los metales debió permanecer aproximadamente

${ }^{16}$ Fuente: cuadro citado por Miguel Othón de Mendizábal en: La minería y la metalurgia mexicana (1520-1943), p. 66. 
NOTAS

\section{Cuadro 7.}

\begin{tabular}{lccc} 
Atios & $\begin{array}{l}\text { Cambio porcs } \\
\text { en el valor } \\
\text { de le producción. }\end{array}$ & \multicolumn{2}{c}{ Cambios porcentuales on producción } \\
$1701-1730$ & & Plate & Oro \\
$1721-1740$ & 39.74 & 40.87 & 29.90 \\
$1741-1760$ & 37.00 & 30.45 & 20.44 \\
$1761-1780$ & 18.15 & 21.73 & 59.77 \\
$1781-1800$ & 50.15 & 53.50 & -6.07
\end{tabular}

Fuente: Cuadros 5 y 6 .

constante a lo largo de todo el siglo XVIII y por lo tanto se comete un error al deflactar los datos, obteniendo de las series deflactadas resultados incorrectos. ${ }^{17}$

De lo hasta aquí dicho puede deducirse que no existe evidencia para decir que la industria estaba en crisis. Del análisis anterior se desprende que, a ni-

${ }^{17}$ En los datos mostrados en el cuadro 5, lo que tenemos es: precio de metales multiplicado por cantidad de metales, el cuadro 6 muestra solo cantidad de metales; como el valor de la producción aumenta aproximadamente lo mismo que la producción, es necesario que los precios permanezcan aproximadamente constantes. En términos de ecuaciones, diríamos que el cuadro 5 muestra algo como lo siguiente: $\mathrm{Po}^{*} \mathrm{Qo}+\mathrm{Pp}^{*} \mathrm{Qp}=\mathrm{VP}$, donde $\mathrm{Po}=$ precio del oro, $\mathrm{Qo}=$ cantidad de oro, $\mathrm{Pp}=$ precio de la plata, $Q p=$ cantidad de plata y VP indica valor de la produccion. EL cuadro 7 muestra que el cambio en VP es aproximadamente igual al cambio en las cantidades, por lo que Po y Pp debieron permanecer constantes o bien tener modificaciones tan pequeñas que el cambio en el precio de los metales debió ser tan mínimo que de ningún modo justifica la deflactación. vel agregado, la minería seguía siendo un negocio lucrativo que estaba muy lejos de ir en decadencia; lo breve de la exposición nos impide decir que la industria tenía pleno crecimiento; sin embargo los datos mostrados tienden a arrojar mas bien este resultado que el de una minería con problemas para sobrevivir. Si medimos la productividad de esta industria considerando el número de trabajadores utilizados y la producción total, nos encontraríamos con algo como lo siguiente: Brading estima que a mediados del siglo XVII el número total de trabajadores de la minería ascendía a 11,000 mientras que en 1800 (siglo y medio más tarde) esta cifra no superaba los $50,000 .{ }^{18}$ Por otra parte, Humboldt sostiene que la producción minera en 1690 era de $5,285,580$ pesos, mientras que en 1800 era de $18,685,674 ;{ }^{19}$ si suponemos que la población utilizada no cambió significativamente de 1650 a 1690 , entonces la productividad por trabajador en este último año era de 480.51 pesos por

\footnotetext{
${ }^{18}$ Brading, op. cit., p. $24,39$.

${ }^{19}$ Humboldt, op. cit., p. 302-3.
} 
trabajador, mientras que en 1800 fue de 373.71 pesos, lo cual indica que la productividad por trabajador se había reducido. Sin embargo, deben tomarse con reserva estos resultados, pues hemos usado el término acuñación como sinónimo de producción y antes hemos visto que hacerlo trae conclusiones equivocadas. Por otra parte, una industria puede estar produciendo en donde la productividad por trabajador sea decreciente y aún así obtener ganancias. ${ }^{20} \mathrm{La}$ observación anterior hace notar que se necesitan más datos para medir la eficiencia de esta industria porque si bien no podemos decir que había crisis, posiblemente si había estancamiento. Esto lo descubriremos hasta que nuevas investigaciones permitan estimar costos de producción y hasta tener parámetros más adecuados para medir la productividad.

\section{III}

En la parte anterior nos hemos encargado de refutar la hipótesis que afirma que en el siglo XVIII la industria minera estaba en crisis. Por otra parte, en la primera parte de este ensayo mencionamos que en sus orígenes, la minería

${ }^{20}$ De hecho, la economía moderna sostiene que una empresa producirá en el punto aquel donde la productividad de los factores productivos presente rendimientos medios decrecientes siempre y cuando sean positivos. En el presente caso, los escasos datos indican que la minería se encontraba en esta situación por lo que no hay indicios que digan que estaba en crisis. fue un sector de la economía novohispánica que motivó el desarrollo de otros sectores pero después dejó de serlo. En las gráficas anteriores puede verse que el declive de la minería se origina en 1810 , de hecho durante prácticamente medio siglo la economía se vio sumida en un pozo que le impidió crecer. $^{21}$

El motivo salta a la vista inmediatamente: la revolución de independencia trajo consigo un declive en la producción de todos los bienes, derivado de la inseguridad que reinaba. Al término de la independencia, unas instituciones políticas y sociales poco sólidas no permitieron definir claramente los derechos de propiedad, a la vez que impidieron la creación de un ambiente propicio para facilitar la producción y el intercambio de bienes y servicios. En términos generales, el objetivo de las instituciones debe ser el de definir los derechos de propiedad asegurando su mantenimiento a través del cumplimiento de las leyes, para crear así incentivos a la producción que a la vez genere cambio tecnológico, y permitiendo de esta manera capturar las ventajas de la disminución de los costos de transacción, ofreciendo bienes a un precio menor, que se traducen en una reducción del riesgo, en la desapari-

${ }^{21}$ Salvucci, Richard and Linda Salvucci, "Las consecuencias económicas de la Independencia", en Leandro Prados de la Escosura and Samuel Amoral, eds., La Independencia Americana Consecuencias Económicas, 1993, Madrid, Alianza, p. 31-53. 


\section{NOTAS}

ción de externalidades y en una mayor especialización. ${ }^{22}$

De este modo, unas instituciones políticas poco sólidas y la lucha intestina por el poder entre conservadores y liberales evitó el crecimiento económico. Por ello, no resulta extraño que el porfiriato haya sido una época de elevado crecimiento, pues el régimen de Díaz logró consolidar las instituciones y posibilitó que los particulares incentivaran el crecimiento de la economía.

\section{IV}

Este ensayo es sólo una gota dentro del océano de investigaciones que se necesitan hacer. En el presente trabajo se habló de la importancia que tuvo el sector minero en la economía de la Nueva España; confirmamos que efectivamente la expansión de este sector tuvo repercusiones positivas en otras áreas de la economía al permitir la expansión de las mismas. La crisis de la minería que Coatsworth sostiene no existió; sus parámetros para medir la eficiencia de esta industria no son los adecuados y aunque lo fueran, sus conclusiones son válidas solamente cuando se deflactan las series que utiliza, en otro caso se derrumban. En páginas anteriores hemos demostrado que no es adecuada la deflactación de los datos que presenta porque el precio de

${ }^{22}$ North, Douglas C. y Robert Paul Thomas, The Rise of the Western World. A New Economic History, 1973, Cambridge, Cambridge University Press, p. 1, 6, 19, 53, 56, $57,89,91,101$. los metales, en general, permaneció aproximadamente constante a lo largo de todo el siglo XVIII y por ello es incorrecto deflactar, pues no se debe descontar un incremento (en precios) que no existió. Por último, la guerra de independencia no permitió un desarrollo económico por la inseguridad reinante en esa época; al finalizar, unas instituciones poco sólidas impidieron un adecuado crecimiento, no sólo del sector minero, sino de toda la economía. Por ello, la minería perdió el impulso que había tenido durante el periodo colonial y su posterior estancamiento evitó que se convirtiera en la industria que pudo conducir a una revolución industrial en México.

Finalmente, recalcamos que los resultados obtenidos deberán ser considerados como parciales hasta que el descubrimiento de nuevos datos, y su análisis, ayuden a confirmar o refutar la idea de que el sector minero no estuvo en crisis durante el siglo XVIII y que los datos obtenidos mas bien apuntan hacia una situación de auge.

\section{Bibliografía}

BRADING, D. A., Mineros y comerciantes en el México borbónico, (1763-1810), 1971, México, Fondo de Cultura Económica.

Humboldt, Alejandro de, Ensayo Político sobre el reino de la Nueva España, 1941, México, ed. Pedro Robledo. COASTWORTH, John H., Los origenes del atraso, 1990, México, Alianza. 
KLEIN, Herbert y John Tepaske, The Seventeenth Century Crisis in New Spain Myth or Reality?, Past and Present, 90, 1981.

MENDIZÁBAL, Miguel Othón de, La minería y la metalurgia mexicana (15201943), 1980, México, Centrode Estudios Históricos del Movimiento Obrero Mexicano.

NORTH, Douglas C. y Robert Paul Thomas, The Rise of the Westem World. A New Economic History, 1973, Cambridge, Cambridge University Press.

PÉrez Herrero, Pedro, El crecimiento económico Novohispano durante el siglo XVII: una revisión, Revista de Historia Económica 7:1, 1989.

SALVUCCI, Richard and Linda Salvucci, "Las consecuencias económicas de la Independencia", en Leandro Prados de la Escosura and Samuel Amoral, eds., La Independencia Americana Consecuencias Económicas, 1993, Madrid, Alianza. 